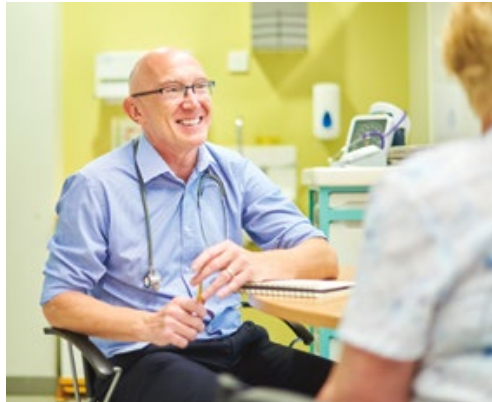

CPD

\section{Michael Wright, Arch G Mainous III}

\section{Background \\ Continuity of care is considered a core component of high-performing primary healthcare systems. As the population and primary care workforce grow, and the burden of chronic disease increases, it is becoming more difficult to provide care from one general practitioner.}

\section{Objectives}

This viewpoint article identifies strategies for encouraging the benefits of continuity of care within a modern health system.

\section{Discussion}

Seeing the same doctor may not be as important as an attitude to provide care consistent with a therapeutic doctorpatient relationship. This attitude may provide the benefits of continuity of care, and should not be lost as our health system becomes more complex.

\title{
Can continuity of care in primary care be sustained in the modern health system?
}

CONTINUITY OF CARE is considered a core feature of both primary care and highperforming primary healthcare systems..$^{1,2}$ Continuity of care traditionally refers to the therapeutic doctor-patient relationship that develops over time. The prototype of this relational continuity of care has been associated with general practices where one general practitioner (GP) provides long-term holistic patient care ('cradleto-grave' medicine). Early authors spoke of continuity of care as underpinning an attitudinal contract between doctors and patients. ${ }^{3}$ In this two-way relationship, patients share information that might assist the doctor in diagnosis, while doctors gain a better understanding of their patients and their preferences. Over time, this relationship (perhaps better termed a partnership) might increase trust between doctor and patient, leading to increased patient compliance, improved shared decision making and improved quality of care.

Continuity of care in terms of the doctor-patient relationship has been associated with positive benefits. Systematic reviews have reported that an increased proportion of care from one doctor (most commonly a GP) is associated with increased patient satisfaction, ${ }^{4}$ decreased emergency department attendance and hospitalisation, ${ }^{5}$ and decreased patient mortality. ${ }^{6}$ Additionally, more concentrated GP care has been associated with increased GP satisfaction. ${ }^{7}$ However, an effect of continuity of care leading to specific improvements in quality of care has not been shown consistently. ${ }^{8}$

\section{Healthcare delivery is experiencing substantial changes}

Many countries, including Australia, have a growing ageing population with an increasing burden of chronic disease. ${ }^{9,10}$ The Australian general practice workforce has also greatly expanded, with GPs tending to work fewer hours and in large multidisciplinary practices. ${ }^{11}$ Broadly speaking, health systems and healthcare delivery have increased in complexity, with greater subspecialisation and more providers involved in patient care. These demographic and workforce trends make it more difficult to provide one-to-one continuity of care for all patients.

Perhaps in response to this increasing complexity, the concept of continuity of care has expanded to include ideas around adequate transfer of information and consistent management across teams of providers, ${ }^{12-14}$ and policy responses have focused on improved coordination of care and information sharing. ${ }^{15}$ Unfortunately, as continuity of care has been redefined to fit the modern healthcare environment, the doctor-patient relationship as the paramount construct in continuity of care seems to get lost. There has been less research investigating the relationship between the broader dimensions of continuity of care and improved health outcomes, and the evidence is less conclusive.

The vision of single-handed GPs and their list of patients harks back to bygone days. As the complexity of the health 
system increases, some authors have questioned whether relational continuity as seen as the doctor-patient relationship is sustainable ${ }^{16}$ or even necessary in modern general practice. ${ }^{17}$ Since there seem to be some positive benefits to continuity of care, a more appropriate health policy question may be how to keep the benefits of continuity of care in the modern health system.

Australians appear to have strong preferences for maintaining continuity of care, with nearly $80 \%$ of people reporting having a usual GP. ${ }^{18}$ Recent research also suggests that $90 \%$ of patients have a usual general practice, although over $25 \%$ of patients report attending multiple practices each year. ${ }^{19}$ This finding suggests that most patients think they may have a doctor-patient relationship, even if they do not get all their care from that one GP. The challenge facing Australian general practice is that without a system for patient registration or enrolment, GPs may be uncertain of who their regular patients are. If GPs do not know they are the usual GP, it appears less likely that the benefits associated with continuity of care and a strong doctor-patient relationship will be provided.

\section{Strategies to encourage continuity of care}

If the modern health system de-emphasises patients receiving the majority of their care from one specific GP, how should we design a health system that will provide the benefits of continuity of care? There are a number of potential strategies.

A first step may be to encourage all patients to identify a regular GP and practice. Encouraging patients to have a regular GP and increasing awareness of the benefits of a strong doctor-patient relationship has been advocated by The Royal Australian College of General Practitioners (RACGP) and the Australian Medical Association. Routinely recording the preferred GP within a practice in the electronic health record may be a practical way to encourage continuity. A more formal approach would be to encourage voluntary patient enrolment with practices, as recommended in the
RACGP's Vision for general practice and a sustainable health system ${ }^{20}$ and by the federal government's Primary Health Care Advisory Group in 2016. ${ }^{21}$

A second step would be for GPs to recognise when patients have identified them as their regular GP and provide care that is consistent with a strong doctorpatient relationship. The role of the regular GP is clear for a patient who consults the same doctor every fortnight, but this may be less apparent for patients attending once or twice a year. Asking patients, 'Is this your usual practice and am I your preferred GP?' or 'Is there somewhere else I should send information about this visit?' may be useful. Once identified, a usual GP should feel empowered to provide holistic long-term care and to provide preventive care, as well as acute treatments. Regular GPs can add patient recalls for appropriate reviews and more actively consider the patient's social circumstance. If a patient identifies with another GP, sending the other GP a copy of consultation notes or copying them in on investigations (particularly if they are in another practice) may be useful strategies.

From a practice perspective, other clinical and administrative staff can be encouraged to facilitate patients to see their preferred GP. One approach would be for practices to identify their regular patients and provide preferential bookings for these patients. There are obvious limitations to scheduling all patient consultations with the same doctor, particularly with many GPs working parttime. Some authors have queried if small practice teams (of two or three GPs and nursing staff) may facilitate continuity effects while being flexible enough to suit current work practices. ${ }^{22}$

A third step would be to provide financial incentives encouraging patients to seek continuity and for GPs to provide continuity. GPs and practices could be paid (perhaps through a restructured Practice Incentives Program or Medicare Benefits Schedule) for providing a greater proportion of care within the practice or providing care consistent with a strong doctor-patient relationship. Although some authors have suggested that enforced continuity may be an option, ${ }^{22}$ the limited evidence to date has failed to show improved health outcomes associated with restricting patient care to the same GP. ${ }^{23}$ It is perhaps not the seeing of the same doctor that provides all the benefits of continuity of care, but rather the attitude of a GP who feels responsible for the wellbeing of the patient. If that is the case, then shifts to practice-based continuity that lose the doctor-patient link, or enforcing continuity by restricting access to other practices, may lead to worse health outcomes unless someone in the practice retains a therapeutic relationship with the patient.

The expansion of the My Health Record program means that all Australians will have access to an electronic repository and summary of their health information before the end of 2018. ${ }^{24}$ This should have the effect of reducing unnecessary pathology testing and improve sharing of health information between all health providers, although issues around privacy and consent may limit the update of the program. There is the potential for other technological advances to encourage more care that is not face to face, but the effect of these advances on patient preferences for continuity of care with one GP is uncertain and requires ongoing research.

As the health system becomes more focused on measurement and evaluation in order to determine the value and quality of care, investigating continuity of care at both a GP and practice level may provide further evidence about the best way to structure delivery of general practice care. Further research into the value of teams within general practices and the role of non-medical practice staff in encouraging strong patient relationships is also needed.

\section{Conclusion}

Although the modern health system in Australia challenges our ability to provide continuity of care, there are some strategies that can be adopted to maintain the doctor-patient relationship in general practice. Patients like continuity. GPs like continuity. Continuity of care has some positive benefits for health outcomes. Serious consideration should be placed on strategies to encourage continuity in the modern health system. 


\section{Authors}

Michael Wright MBBS, MSc, FRACGP,

$\mathrm{PhD}$ candidate, Centre for Health Economics Research and E valuation, University Technology Sydney, NSW

Arch G Mainous III, PhD, Florida Blue Endowed Professor and Chair, Department of Health Services Research, Management and Policy; Professor and Vice Chair for Research, Department of Community Health and Family Medicine, University of Florida, USA Competing interests: None.

Funding: Dr Wright has been supported by an Australian Government Research Training Program Scholarship.

Provenance and peer review: Commissioned, externally peer reviewed.

\section{References}

1. Bodenheimer T, Ghorob A, Willard-Grace R Grumbach $\mathrm{K}$. The 10 building blocks of highperforming primary care. Ann Fam Med 2014;12(2):166-71. doi: 10.1370/afm.1616.

2. Macinko J, Starfield B, Shi L. The contribution of primary care systems to health outcomes within Organization for Economic Cooperation and Development (OECD) countries, 1970-1998. Health Serv Res 2003;38(3):831-65.

3. Banahan BF Jr, Banahan BF 3rd. Continuity as an attitudinal contract. J Fam Pract 1981;12(4):767-68.

4. Adler R, Vasiliadis A, Bickell N. The relationship between continuity and patient satisfaction: $A$ systematic review. Fam Pract 2010;27(2):171-78. doi: 10.1093/fampra/cmp099.

5. van Walraven $\mathrm{C}$, Oake N, Jennings A, Forster AJ. The association between continuity of care and outcomes: A systematic and critical review. J Eval Clin Pract 2010;16(5):947-56. doi: 10.1111/j.13652753.2009.01235.x.

6. Pereira Gray DJ, Sidaway-Lee K, White E, Thorne A, Evans $\mathrm{PH}$. Continuity of care with doctors-A matter of life and death? A systematic review of continuity of care and mortality. BMJ Open 2018;8(6):e021161. doi: 10.1136/bmjopen-2017021161.

7. Stokes T, Tarrant C, Mainous AG, Schers $H$, Freeman G, Baker R. Continuity of Care: Is the personal doctor still important? A survey of general practitioners and family physicians in England and Wales, the United States, and the Netherlands. Ann Fam Med 2005;3(4):353-59. doi: 10.1370/afm.351.

8. Gill JM, Mainous AG 3rd, Diamond JJ, Lenhard MJ. Impact of provider continuity on quality of care for persons with diabetes mellitus. Ann Fam Med 2003;1(3):162-70.

9. Australian Institute of Health and Welfare (AIHW). Australia's Health 2016. Canberra: AIHW, 2016.

10. Nolte E, McKee M. Measuring the health of nations: Analysis of mortality amenable to health care. BMJ 2003;327(7424):1129. doi: 10.1136/ bmj.327.7424.1129.

11. Britt H, Miller G, Valenti L, Henderson J, Bayram C Gordon J. The changing face of Australian general practice across the decades. Aust Fam Physician 2016;45(9):628-31.

12. Hennen BK. Continuity of care in family practice. Part 1: Dimensions of continuity. J Fam Pract 1975;2(5):371-72.

13. Freeman G, Shepperd S, Robinson I, Ehrich K, Richards S. Continuity of care: Report of a scoping exercise for the National Co-ordinating Centre for NHS Service Delivery and Organisation R \& D (NCCSDO). London: NCCSDO, 2001.

14. Reid RJ, Haggerty J, McKendry R. Defusing the confusion: Concepts and measures of continuity of healthcare. Ottawa: Canadian Health Services Research Foundation, 2002.

15. Guthrie B, Saultz JW, Freeman GK, Haggerty JL. Continuity of care matters. BMJ 2008;337:a867. doi: 10.1136/bmj.a867.

16. Bonney A, Farmer E. Health care reform - Can we maintain personal continuity? Aust Fam Physician 2010;39(7):455-56.
17. Freeman $G$, Hjortdahl P. What future for continuity of care in general practice? BM 1997;314(7098):1870-73.

18. Australian Bureau of Statistics (ABS). Patient experiences in Australia: Summary of findings, 2016-17. Canberra, Australia: ABS, 2017.

19. Wright M, Hall J, van Gool K, Haas M. How common is multiple general practice attendance in Australia? Aust J Gen Pract 2018;47(5):289-96.

20. RACGP. Vision for general practice and a sustainable healthcare system. Melbourne: RACGP, 2015. Available at www.racgp. org.au/download/Documents/advocacy/ racgp-vision-for-general-practice-and-asustainable-health-system.pdf [Accessed 29 August 2018].

21. Department of Health. Better outcomes for people with chronic and complex health conditions. Canberra: Commonwealth of Australia, 2015 Available at www.health.gov.au/internet/main/ publishing.nsf/content/primary-phcag-report [Accessed 29 August 2018]

22. Mainous AG 3rd, Salisbury C. Advanced access, open access, and continuity of care: Should we enforce continuity? Fam Med 2009;41(1):57-58.

23. Barker I, Lloyd T, Steventon A. Effect of a national requirement to introduce named accountable general practitioners for patients aged 75 or older in England: Regression discontinuity analysis of general practice utilisation and continuity of care. BMJ Open 2016;6(9):e011422. doi: 10.1136/bmjopen-2016-011422.

24. Australian Digital Health Agency. What is My Health Record? Canberra: Australian Digital Health Agency, 2018. Available at www. myhealthrecord.gov.au/for-you-your-family/whatis-my-health-record [Accessed 24 April 2018].

correspondence ajgp@racgp.org.au 